Article

\title{
Separating the Impacts of Climate Variation and Human Activities on Runoff in the Songhua River Basin, Northeast China
}

\author{
Fengping Li ${ }^{1,2}$, Guangxin Zhang ${ }^{1, *}$ and $\mathrm{Yi}$ Jun $\mathrm{Xu}^{3}$
}

1 Northeast Institute of Geography and Agroecology, Chinese Academy of Sciences, Changchun 130102, Jilin, China; E-Mail: fengpingli2014@yahoo.com

2 University of Chinese Academy of Sciences, Beijing 100049, China

3 School of Renewable Natural Resources, Louisiana State University Agricultural Center, Baton Rouge, LA 70803, USA; E-Mail: yjxu@1su.edu

* Author to whom correspondence should be addressed; E-Mail: zhgx@neigae.ac.cn; Tel.: +86-431-8554-2210; Fax: +86-431-8554-2298.

External Editor: Ataur Rahman

Received: 27 August 2014; in revised form: 13 October 2014 / Accepted: 31 October 2014 / Published: 7 November 2014

\begin{abstract}
Climate variation and human activities are commonly recognized as two major factors affecting basin hydrology. However, quantifying their individual effect on runoff is challenging. In this study, long-term (1960-2009) river discharge and weather data in the Songhua River Basin (SRB, 556,800 km²), Northeast China, were gathered to separate the impacts of climate variation and human activities on runoff in five sub basins of the SRB. Mann-Kendall test, moving t-test and precipitation-runoff double cumulative curve were utilized to identify trends and change points of the hydrometeorlogical variables. Based on the change point, the 50-year study period was divided into two time series: 1960-1974 where minimal human activities took place and 1975-2009 where extensive land use change occurred and river engineering projects were undertaken. Subsequently, individual contributions of climate and human factors were assessed through a hydrologic sensitivity analysis. Our study found a significant decline in runoff of the SRB over the past 50 years. Contribution of climate variation and human activities to the change varied temporally and spatially. For the 1975-2009 period, human activities made a greater contribution $(62 \%-82 \%)$ to the total runoff decline of the SRB. However, climate variation played a bigger role in runoff reduction in two sub river basins (63\%-65\%) between 1975 and 1989 ,
\end{abstract}


as well as in runoff increase in other two sub river basins (85\%-86\%) between 1990 and 1999. Spatially, the effect of human activities on runoff decline was relatively stronger in the lower basin areas in the 1960s and 1970s while showing an increasing role in the upper basin areas in the past two decades.

Keywords: river basin runoff; precipitation-runoff relation; hydrologic sensitivity analysis; climate variation; human activities; Nenjiang River; Second Songhua River; Songhua River

\section{Introduction}

In recent decades, streamflow decline has been observed in many rivers throughout the world. For instance, Banasik et al. [1,2] reported a decreasing trend of runoff in the Zagożdżonka catchment in central Poland; Pekarova et al. [3] showed the long-term trends and runoff fluctuations of many rivers in Europe; In China, many large rivers have experienced a strong decreasing trend in discharge (e.g., the Yellow River in Central China [4], the Tarim River in West China [5], and the Songhua River in Northeast China [6]). Factors that could have affected the change include both climatic variation (e.g., changes in precipitation and temperature) and anthropogenic activities (e.g., land use change, dam construction, and river engineering). There has been an ongoing debate as to which of the two factors has played a greater role in the changes of discharge from the river basins.

A number of studies have been conducted to separate the impact of climate variation and human activities on river discharge [7-9]. Using regression techniques Ye et al. [10] and Tian et al. [11] investigated the effects of climate variability and human activities on the long-term change in runoff of the Lena River Basin and Hutuo River Basin in China; however, a clear conclusion on the magnitude of each of the two factors could not be drawn due to the limitation of the analytical method. Using hydrologic simulation other researchers [12-14] reconstructed long-term runoff time series that were then used for separation of the climate variation and human activity effects on river basin runoff. In the recent decade, Dooge et al. [15] and Milly and Dunne [16] introduced a hydrologic sensitivity analysis approach to separate the effect of climate change on runoff from that of human activities by isolating the precipitation and potential evapotranspiration effects. The approach found wide applications for various climatic regions in the world [17-22].

For a given river basin, runoff can exhibit spurious changes [23]. Determining a spurious change-point in long-term runoff records is therefore necessary for assessing individual contribution of climate variation and human activities on basin runoff. This can be done using statistical approaches (e.g., non-parametric tests and time series analysis) combined with graphical methods (e.g., double mass curves, single mass curves and flow duration curves) [24,25]. In their study on assessing the impacts of climate variation and human activities on river runoff, for instance, Zhao et al. [21] identified a spurious change point and defined the period before the change point as a natural period (i.e., with little or no human disturbance) to estimate the effect of climate variation on runoff.

The Songhua River Basin (SRB) is one of China's most important commodity grain production bases. It is also the largest inland wetland region with diverse freshwater marshes, fens, bogs, peat swamps, and wet meadows. Stream and river discharge in the SRB are the mostly used water sources for 
agricultural irrigation, industry, and public supplies. The surface water source is also crucial for the large area of wetlands in the region that support diverse ecosystems and many endangered wildlife species including six of the world's fifteen crane species. In the past half century, climate in the SRB has become warmer and drier [6] and a large area of wetlands has degraded while farmland has been increasing rapidly within the river basin [26]. At the same time large-scale river engineering projects (primarily, construction of dams and ditches) were completed in the basin to meet the increased water use demand for agriculture, industry, and public [27]. A recent study [6] found a decreasing trend of discharge in all major tributaries of the SRB over the past half century. The reduction in discharge has raised the concern over wetland shrinkage and biodiversity loss in the river basin. In order to develop best management strategies for effective utilization and protection of the limited water resources in the SRB, it is of both scientific interest and practical relevance for integrated river basin management to gain insights into individual contribution of the climate variation and human activities to the discharge decline from the basin. There are several studies addressing the change and its influencing factors in the SRB [28,29], but these studies neglected land use effects across the SRB.

Land use change has been found globally to be a major factor affecting river basin runoff. Up to now, to the best of our knowledge, detailed analysis on the long-term change in runoff of the SRB and the individual contribution of climatic variation and human activities have not been reported. The objectives of this study were to: (1) assess long-term runoff change in five major tributary basins of the SRB; (2) detect critical change points of annual runoff in these basins; and (3) quantitatively evaluate the individual contribution of climate variation and human activities to the runoff change across the SRB.

\section{Study Area}

The Songhua River Basin is located in the far northeast of China stretching longitudinally from $119^{\circ} 52^{\prime} \mathrm{E}$ to $132^{\circ} 31^{\prime} \mathrm{E}$ and latitudinally from $41^{\circ} 42^{\prime} \mathrm{N}$ to $51^{\circ} 38^{\prime} \mathrm{N}$ (Figure 1). It is one of China's seven major river basins, covering a total land area of $556,800 \mathrm{~km}^{2}$. The river basin comprises a large portion of Heilongjiang Province, Jilin Province, and northeastern Inner Mongolia Autonomous Region.

Two major tributaries drain the SRB: the Nenjian River (the northern source) and the Second Songhua River (the southern source). The Nenjiang River tributary originates from the Yilehuli Mountain in the Great Khingan Mountains, traveling $1370 \mathrm{~km}$ from northwest to southeast and draining $297,000 \mathrm{~km}^{2}$ land. The Second Songhua River originates from Tianchi Lake in the Changbai Mountain and flows $958 \mathrm{~km}$ from southeast to northwest draining a land area of 73,400 $\mathrm{km}^{2}$. With gentle slope and wide river channel, the Lower Songhua River carries the combined flow from the Nenjiang and Second Songhua Rivers and flows $939 \mathrm{~km}$ northeastward before entering the Amur River. The elevation of the SRB varies from 50 to $2700 \mathrm{~m}$ above sea level, with an extensive floodplain — the Songnen Plain —in the middle of the basin after the confluence of the Nenjian and Second Songhua Rivers.

Climatic and hydrologic conditions of the SRB are complex because of the large geographical extent and elevation difference. Long-term mean annual precipitation is about $455 \mathrm{~mm}$ in the Nenjiang River Basin (NRB), $668 \mathrm{~mm}$ in the Second Songhua River Basin (SSRB), and $563 \mathrm{~mm}$ in the entire SRB [6]. Monthly average temperature has been reported to be $3.2{ }^{\circ} \mathrm{C}, 4.2{ }^{\circ} \mathrm{C}$ and $3.5{ }^{\circ} \mathrm{C}$, respectively, in the $\mathrm{NRB}, \mathrm{SSRB}$ and the entire SRB [6]. Long-term average annual potential evapotranspiration (PET) is estimated for $877 \mathrm{~mm}$ in the SRB, fluctuating from 839 to $945 \mathrm{~mm}$. 
Figure 1. The Songhua River Basin and its two tributary basins (the Nenjiang River Basin and the Second Songhua River Basin) in northeast China and the gauge (dots) and meteorological (stars) stations used in this study.

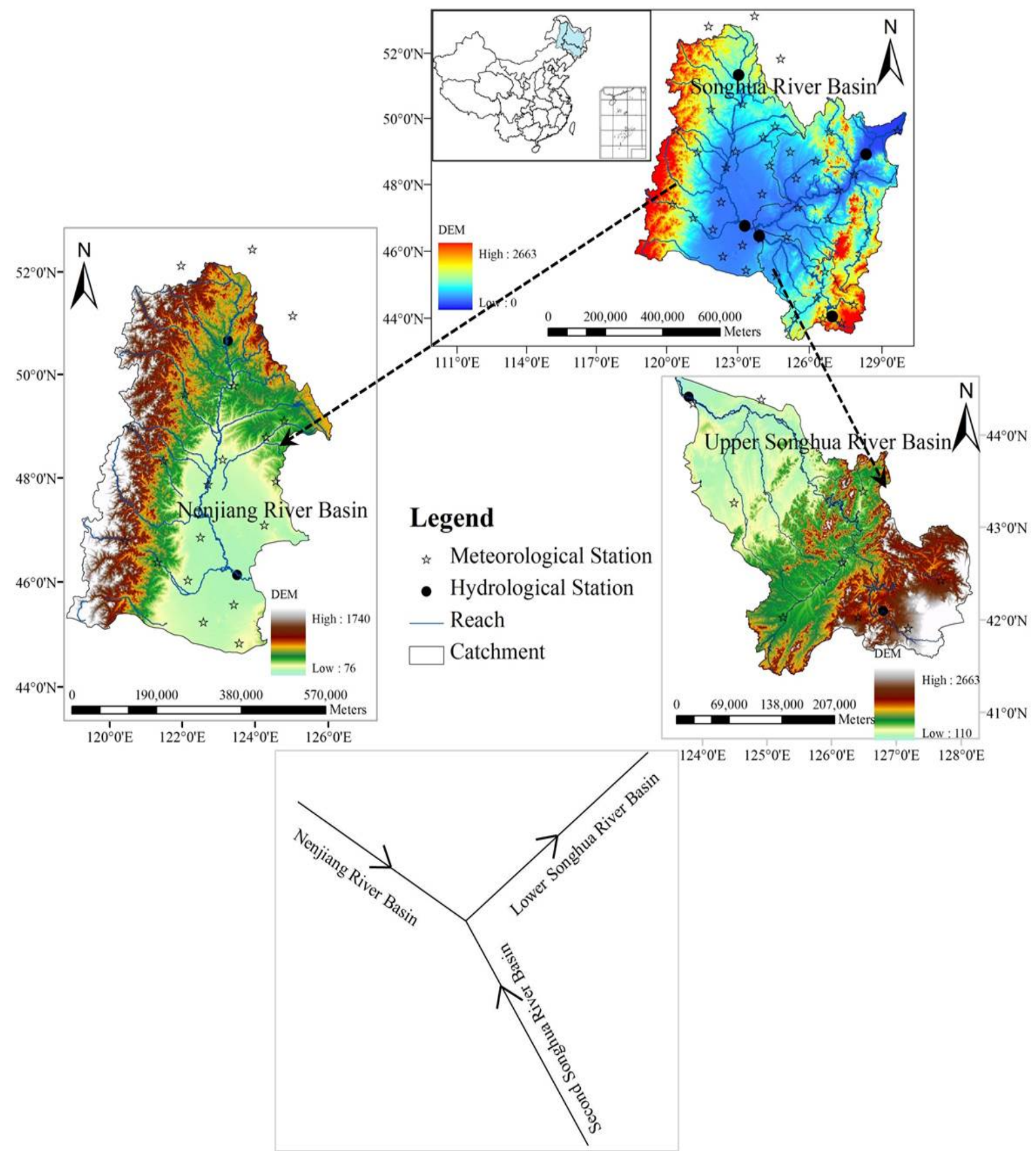

Besides being one of the major grain production bases in China, the SRB is also China's largest inland wetland region with many nature preserves and national parks. The Songhua River is a major source for industry, agriculture, and public drinking water supplies in Northeast China. Therefore, the analysis of the runoff variations and its sensitivity to climate variation and human activities is of great importance. 


\section{Available Data and Methods}

\subsection{Data Collection}

Meteorological data were collected from 40 national weather stations relatively evenly distributed across the Songhua River Basin (Figure 1). Monthly data were used to calculate potential evapotranspiration using the Penman-Monteith equation recommended by the Food and Agriculture Organization (FAO) [30]. The average precipitation and PET for each sub river basin were estimated using the Thiessen Polygon method.

Monthly discharge records for the period from 1960 to 2009 were obtained from five gauge stations (Figure 1) that represent the total discharge of the five drainage areas (Table 1). Selection of the gauge stations was intended to determine runoff changes in (1) the upper river basin areas of the two tributaries of the Songhua River - the Nenjiang and Second Songhua Rivers; (2) the lower river basin areas of the two tributaries; and (3) the lower Songhua River Basin. Specifically, discharge at the Shihuiyao and Gaolichengzi stations were used to represent flows from the Upper NRB (UNRB) and Upper SSRB (USSRB), respectively; the difference between discharge at the Dalai and Shihuiyao stations was used as the discharge from the Lower NRB (LNRB); the difference in discharge between the Fuyu and Gaolichengzi stations was used as the discharge from the Lower SSRB (LSSRB); the difference in discharge between the Jiamusi and the sum of discharge at the Dalai and Fuyu stations was used to represent flows from the Lower SRB (LSRB). Monthly discharge data from the stations were used to compute monthly flow volume for each of the five sub river basins. The flow volumes were then divided by the representing drainage areas to obtain monthly runoff in depth.

Table 1. Location, drainage area, and representative gauge stations of the Upper Nenjiang River Basin (UNRB), Lower Nenjiang River Basin (LNRB), Upper Second Songhua River Basin (USSRB), Lower Second Songhua River Basin (LSSRB), and Lower Songhua River Basin (LSRB) in Northeast China.

\begin{tabular}{ccccc}
\hline Basin & Gauge station & Longitude $\left({ }^{\circ} \mathbf{E}\right)$ & Latitude $\left({ }^{\circ} \mathbf{N}\right)$ & Drainage Area $\left(\mathbf{k m}^{2}\right)$ \\
\hline UNRB & Shihuiyao & $125^{\circ} 19^{\prime} 12^{\prime \prime}$ & $50^{\circ} 03^{\prime} 00^{\prime \prime}$ & 17,205 \\
LNRB & Dalai & $124^{\circ} 16^{\prime} 12^{\prime \prime}$ & $45^{\circ} 33^{\prime} 00^{\prime \prime}$ & 204,510 \\
USSRB & Gaolichengzi & $127^{\circ} 13^{\prime} 48^{\prime \prime}$ & $42^{\circ} 21^{\prime} 00^{\prime \prime}$ & 4,728 \\
LSSRB & Fuyu & $124^{\circ} 49^{\prime} 12^{\prime \prime}$ & $45^{\circ} 10^{\prime} 12^{\prime \prime}$ & 67,055 \\
LSRB & Jimusi & $130^{\circ} 19^{\prime} 12^{\prime \prime}$ & $46^{\circ} 48^{\prime} 00^{\prime \prime}$ & 234,799 \\
\hline
\end{tabular}

Furthermore, we collected land use/land cover (LULC) maps for 1975, 1986, 1996 and 2005. Changes in nine LULC categories, including paddy farmland, dry farmland, forest, grassland, open water, reservoir \& pond, residential \& industry land, bared land, and wetland, were quantified for NRB, SSRB and LSRB.

\subsection{Trend Analysis}

The Mann-Kendall test $[31,32]$ was applied to analyze the trend of temporal variations of climatic parameters and river basin runoff. In the Mann-Kendall test, the null hypothesis $H_{0}$ states that $x_{1}, \ldots, x_{n}$ are samples of $n$ independent and identically distributed random variables with no seasonal change. The 
alternative hypothesis $H_{l}$ for a two-sided test defines the distributions of $x_{k}$ and $x_{i}$ as non-identical for all $k, j \leq n$; with $k \neq j$. The test statistic $S$ is given as:

$$
\begin{gathered}
S=\sum_{i=1}^{n-1} \sum_{k=i+1}^{n} \operatorname{sgn}\left(x_{k}-x_{i}\right) \\
\operatorname{sgn}(\theta)=\left\{\begin{array}{cc}
1 & \theta>0 \\
0 & \theta=0 \\
-1 & \theta<0
\end{array}\right.
\end{gathered}
$$

If the data set is independent and identically distributed, then the mean of $S$ will be zero and the variance of $S$ will be:

$$
\operatorname{var}(s)=\left[n(n-1)(2 n+5)-\sum_{j=1}^{m} t_{j}\left(t_{j}-1\right)\left(2 t_{j}+5\right)\right] / 18
$$

where $n$ is the number of data points; $t$ is the extend of a given time; $m$ is the number of tied groups; and $t_{j}$ is the number of data points in the $j$-th group. A tied group is a set of data points that have the same value. A normalized test statistic $Z$ can be computed based on $S$ as follows:

$$
Z=\left\{\begin{array}{c}
\frac{S-1}{\sqrt{\operatorname{var}(\mathrm{S})}}, S>0 \\
0, S=0 \\
\frac{S+1}{\sqrt{\operatorname{var}(\mathrm{S})}, S<0}
\end{array}\right.
$$

When the significance levels are set at $0.01,0.05$ and $0.1,\left|Z_{\alpha}\right|$ is $2.58,1.96$, and 1.65 , respectively. At certain significance level, if $|Z|>\left|Z_{\alpha}\right|$, the null hypothesis $\mathrm{H}_{0}$ is rejected. In other words, the trend is significant at the set level of significance. Otherwise, no significant trend exists.

The Mann-Kendall test assumes that the time series data are independent $[33,34]$. However, certain hydrological time series may frequently display statistically significant serial correlation. Therefore, in order to eliminate the influence of serial correlation, "pre-whitening" was proposed by Von Storch [35] to remove the lag-1 serial correlation $\left(r_{1}\right)$ from the time series.

To determine whether the observed data set is serially correlated, the significance of the lag-1 serial correlation $\left(r_{1}\right)$ should be tested at the 0.10 significance level. $r_{1}$ is calculated using the following formula:

$$
\mathrm{r}_{k}=\frac{\frac{1}{n-k} \sum_{i=1}^{n-k}\left(x_{i}-\bar{x}\right)\left(x_{i+k}-\bar{x}\right)}{\frac{1}{n} \sum_{i=1}^{n}\left(x_{i}-\bar{x}\right)^{2}}
$$

If $\frac{-1-1.645 \sqrt{n-2}}{n-1} \leq r_{1} \leq \frac{-1+1.645 \sqrt{n-2}}{n-1}$, the time series is assumed to be independent at the 0.10 significance level and can be subjected to the original Mann-Kendall test. Otherwise, the effect of serial correlation should be removed from the time series by pre-whitening prior to applying the 
Mann-Kendall test, and the Mann-Kendall test was then used to detect a trend in the residual series. The new time series was obtained as follows:

$$
x_{i}^{\prime}=x_{i}-(\beta \times i)
$$

The $r_{1}$ value of this new time data set was calculated and used to determine the residual series as:

$$
y_{i}^{\prime}=x_{i}^{\prime}-r_{1} \times-x_{i-1}^{\prime}
$$

The value of $\beta \times i$ was added again to the residual data set as follows:

$$
y_{i}=y_{i}^{\prime}+(\beta \times i)
$$

The $y_{i}$ series was subjected to trend analysis.

\subsection{Change-Point Detection}

A moving $t$-test was conducted to analyze the change point of the hydrometeorological series. In moving $t$-test, an $n$-sample series was divided by random variables into sub-sequences $x_{1}$ and $x_{2}$, whose data length was $n_{1}$ and $n_{2}$, respectively. The sub-sequences have their own mean value of $\overline{x_{1}}$ and $\overline{x_{2}}$, and variance of $s_{1}$ and $s_{2}$. The statistic is defined as:

$$
\begin{gathered}
t=\frac{\bar{x}_{2}-\bar{x}_{1}}{s \sqrt{\frac{1}{n_{1}}+\frac{1}{n_{2}}}} \\
s=\sqrt{\frac{\left(n_{1}-1\right) s_{1}^{2}+\left(n_{2}-1\right) s_{2}^{2}}{n_{1}+n_{2}-2}}
\end{gathered}
$$

where the statistic $t$ obeys the distribution of $t\left(n_{1}+n_{2}-2\right)$. Given the significance level of $\alpha$, the null hypothesis of no difference will be rejected if $\left|t_{0}\right|>t_{\alpha / 2}$, indicating a significant difference between $x_{1}$ and $x_{2}$.

In addition, the precipitation-runoff double cumulative curve (DCC) was generated to identify change-points of the runoff series. The precipitation-runoff DCC analysis provides a visual representation of the consistency of the precipitation and runoff data [36]. It should be a straight line if two variables are proportional, and the slope of this line will present the ratio between the two variables. Changes in the gradient of the curve may indicate that the characteristics of the precipitation or runoff have changed. In this study, DCC between precipitation and runoff was used as an auxiliary confirmation of the change points when human activities imposed the influences on the river.

Through the trend and change-point analysis, the runoff series were divided into (1) a reference period where little to no anthropogenic disturbance occurred in the river basin; and (2) other time periods when intensive human activities took place. Based on the period division, the contribution of climate variation and human activities on runoff were separated through the following approach.

\subsection{Quantitative Assessment of the Effects of Climate Variation and Human Activities on the Runoff}

A change in mean annual runoff can be calculated as follows: 


$$
\Delta R_{o b s}=\bar{R}_{o b s, 2}-\bar{R}_{o b s, 1}
$$

where $\Delta R_{o b s}$ indicates the observed change in mean annual runoff between two different periods; $\bar{R}_{\text {obs }, 1}$ is the average annual runoff during the reference period; and $\bar{R}_{o b s, 2}$ is the average annual runoff during other periods.

Climate variation and human activities are two main driving factors affecting the change of catchment hydrology. Although they are inter-related, we attempt to assess their individual impact on runoff in this study. As a first-order approximation, the total change in mean annual runoff can be estimated as:

$$
\Delta R_{o b s}=\Delta R_{c \lim }+\Delta R_{h u m}
$$

where $\Delta R_{c l i m}$ and $\Delta R_{h u m}$ indicate the changes in the mean annual runoff due to climate variation and human activities, respectively.

Jones et al. [18] and Ma et al. [37] used percentage changes in runoff in response to the change in precipitation and potential evapotranspiration to weigh out the role of climate variation versus land use change. The concept is based on a water balance for a river basin:

$$
P=A E T+R+\Delta S
$$

where $P$ is the precipitation ( $\mathrm{mm}) ; A E T$ is the actual evapotranspiration (mm); $R$ is the runoff (mm); and $\Delta S$ is the change in the basin water storage $(\mathrm{mm})$. Over a long period of time (i.e., equal to or greater than 10 years), $\Delta S$ can be assumed as zero.

Using an equation developed by Zhang et al. [38], the actual evapotranspiration (AET) can be estimated as follows:

$$
\text { AET } / P=(1+w(P E T / P)) /\left(1+w(P E T / P)+(P E T / P)^{-1}\right)
$$

where PET is the potential evapotranspiration; and $w$ is a model parameter related to the vegetation type, soil hydraulic property, and topography [38]. $w$ can be obtained using long-term hydrometeorological data and estimates of potential evapotranspiration through:

$$
w=(A E T(1+P / P E T)-P) / P E T(1-A E T / P)
$$

In this study, we estimated AET with Equation (13) and PET with the Penman-Monteith equation, and then calculated $w$ with Equation (15) for different time periods to reflect changes in vegetation cover.

Variation in both precipitation and PET can lead to changes in the water balance. Based on the hydrologic sensitivity relationship, the change in mean annual runoff due to climate variation $\left(\Delta R_{c l i m}\right)$ can be approximated as follows [16,39]:

$$
\Delta R_{c \lim }=\beta \cdot \Delta P+\gamma \cdot \Delta P E T
$$

where $\triangle P$ and $\triangle P E T$ are changes in mean annual precipitation and potential evapotranspiration respectively; $\beta$ and $\gamma$ are the sensitivity parameters given as [19]:

$$
\begin{gathered}
\beta=(1+2 x+3 w x) /\left(1+x+w x^{2}\right)^{2} \\
\gamma=-(1+2 w x) /\left(1+x+w x^{2}\right)^{2}
\end{gathered}
$$

where $x$ is the dryness index (equal to PET/P); $w$ is same as in Equations (14) and (15). 
Once $\Delta R_{c l i m}$ is obtained, $\Delta R_{h u m}$ can be known using Equation (12). The relative contribution of climate variation and human activities on runoff can be then expressed in percentage as follows:

$$
\begin{aligned}
& \eta_{c \lim }=\frac{\Delta R_{c \lim }}{\left|\Delta R_{o b s}\right|} \times 100 \% \\
& \eta_{\text {hum }}=\frac{\Delta R_{\text {hum }}}{\left|\Delta R_{\text {obs }}\right|} \times 100 \%
\end{aligned}
$$

where $\eta_{c l i m}$ and $\eta_{\text {hum }}$ are the percentage of the climate-variation-induced impact and human-activity-inducted impact on runoff, respectively.

\section{Results}

\subsection{Long-Term Changes in Precipitation and Potential Evapotranspiration}

Over the past 50 years, the entire Songhua River Basin showed an increasing trend of temperature, but a decreasing trend of precipitation (Figure 2) with an average reduction of $6 \mathrm{~mm} / 10 \mathrm{a}$. The annual precipitation in the SRB averaged $563 \mathrm{~mm}$, with the highest $(716 \mathrm{~mm}$ ) occurred in 1998 and the lowest (428 mm) occurred in 2001 (Figure 2). Spatially, the average annual precipitation varied from $450 \mathrm{~mm}$ in LNRB to $815 \mathrm{~mm}$ in USSRB. The precipitation in SSRB was higher than that in NRB, and the upper basins had higher precipitation than lower basins in NRB and SSRB (Table 2).

Figure 2. Annual values (dots) and trends (dashed line) of mean temperature (a); precipitation (b); potential evapotranspiration (PET) (c); and runoff (d) for 1960-2009 in the Songhua River Basin, Northeast China.
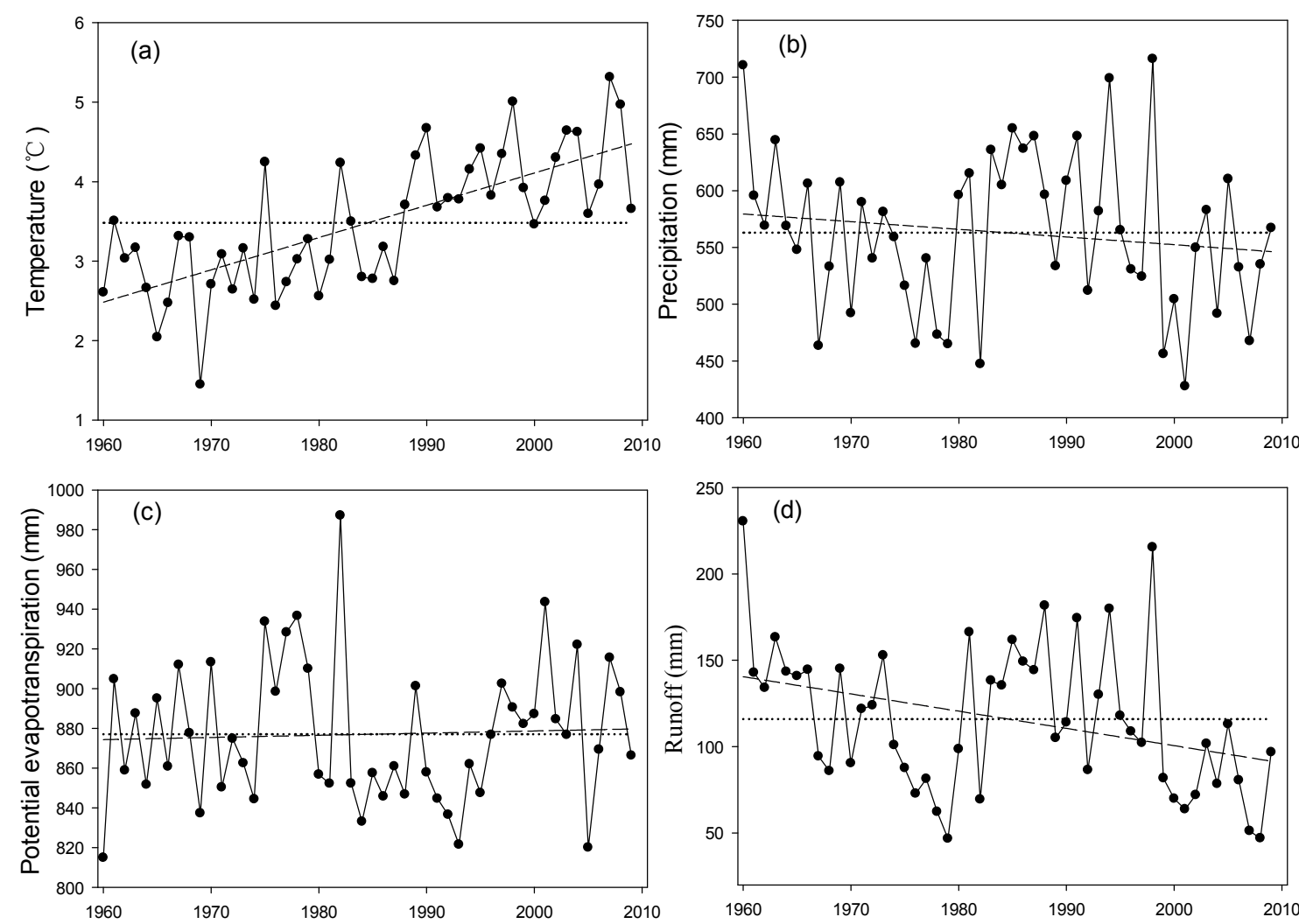
Table 2. Averages of precipitation $(\mathrm{P})$, potential evapotranspiration $(\mathrm{PET})$ and runoff $(\mathrm{R})$ in Upper Nenjiang River Basin (UNRB), Lower Nenjiang River Basin (LNRB), Upper Second Songhua River Basin (USSRB), Lower Second Songhua River Basin (LSSRB), and Lower Songhua River Basin (LSRB), Northeast China.

\begin{tabular}{ccccc}
\hline Basin & Gauge Station & P $(\mathbf{m m})$ & PET $(\mathbf{m m})$ & R $(\mathbf{m m})$ \\
\hline UNRB & Shihuiyao & 507 & 731 & 161 \\
LNRB & Dalai & 450 & 963 & 81 \\
USSRB & Gaolichengzi & 815 & 814 & 493 \\
LSSRB & Fuyu & 656 & 842 & 173 \\
LSRB & Jimusi & 563 & 847 & 112 \\
\hline
\end{tabular}

Despite a clear increasing trend of temperature over the past half century, potential evapotranspiration for the entire SRB showed a slight increase. According to the trend analysis (Table 3), the PET increase rate was $1 \mathrm{~mm} / 10 \mathrm{a}$. With a mean value of $877 \mathrm{~mm}$, the estimated potential evapotranspiration in the SRB varied from $814 \mathrm{~mm}$ in 1960 to $987 \mathrm{~mm}$ in 1982 (Figure 2). From the spatial aspect, the average annual PET varied from 731 to $963 \mathrm{~mm}$, with the highest value occurring in LNRB and the lowest in UNRB.

Table 3. Trend and change-point analysis of annual precipitation, potential evapotranspiration (PET) and runoff in the Songhua River Basin, Northeast China.

\begin{tabular}{|c|c|c|c|c|c|}
\hline \multirow{2}{*}{ Factor } & \multirow{2}{*}{$\begin{array}{c}\text { Mean Value } \\
(\mathbf{m m} / \mathbf{a})\end{array}$} & \multirow{2}{*}{$\begin{array}{c}\text { Trend Rate } \\
(\mathbf{m m} / \mathbf{1 0} \text { a) }\end{array}$} & \multicolumn{2}{|c|}{ Mann-Kendall Test } & \multirow{2}{*}{$\begin{array}{c}\text { Moving t-test } \\
\text { Change-Point Analysis }\end{array}$} \\
\hline & & & $\mathbf{Z}$ & Positive Significance & \\
\hline Precipitation & 563 & -6 & -0.74 & - & - \\
\hline PET & 878 & 1 & 0.27 & - & - \\
\hline Runoff & 116 & -10 & -2.61 & 0.95 & 1974 \\
\hline
\end{tabular}

\subsection{Long-Term Changes in Runoff and Change Point Detection}

Annual runoff from the entire Songhua River Basin showed an average of $116 \mathrm{~mm}$ for the 50-year period of 1960-2009, fluctuating largely from nearly $47 \mathrm{~mm}$ in the dry years of 1979 and 2008 to more than $200 \mathrm{~mm}$ in the wet years of 1960 and 1998 (Figure 2). During the same period, average runoff of the SRB showed a significantly $(Z=-2.61 ; \alpha=95 \%)$ considerable decline at a rate of $10 \mathrm{~mm} / 10$ a (Table 3 ). Spatially, the average runoff was lowest in LNRB $(81 \mathrm{~mm})$ and highest in USSRB $(493 \mathrm{~mm})$, and varied from 112 to $173 \mathrm{~mm}$ in UNRB, LSSRB and LSRB. Concurrently, spatial difference in the runoff decline exists. As reported in our previous study [6], significant decreasing trends in runoff were observed mainly in the LSRB, and magnitude of the decreasing trends was more apparent in the downstream than that in the upstream, all in the NRB, SSRB and LSRB.

A change-point in runoff was detected for the year of 1974 by moving-t test in the SRB (Table 3). The relationship of cumulative annual precipitation and runoff (Figure 3) demonstrated that in all the three basins (NRB, SSRB and LSRB), precipitation and runoff were relatively uniform before 1974 and changed thereafter. Combined analysis of these two methods indicated that 1974 could be the change-point reflecting the effect of human activities on runoff in SRB. Therefore, the 50-year study period was divided into two time series: 1960-1974 where minimal human activities took place and 
1975-2009 where land use change and river engineering projects were undertaken, which was divided into three durations: 1975-1989, 1990-1999 and 2000-2009 for further analysis.

Figure 3. Double cumulative curve (DCC) of annual precipitation and runoff in the Songhua River Basin (SRB) and its two tributary basins, the Nenjiang River Basin (NRB) and Second Songhua River Basin (SSRB) in Northeast China.
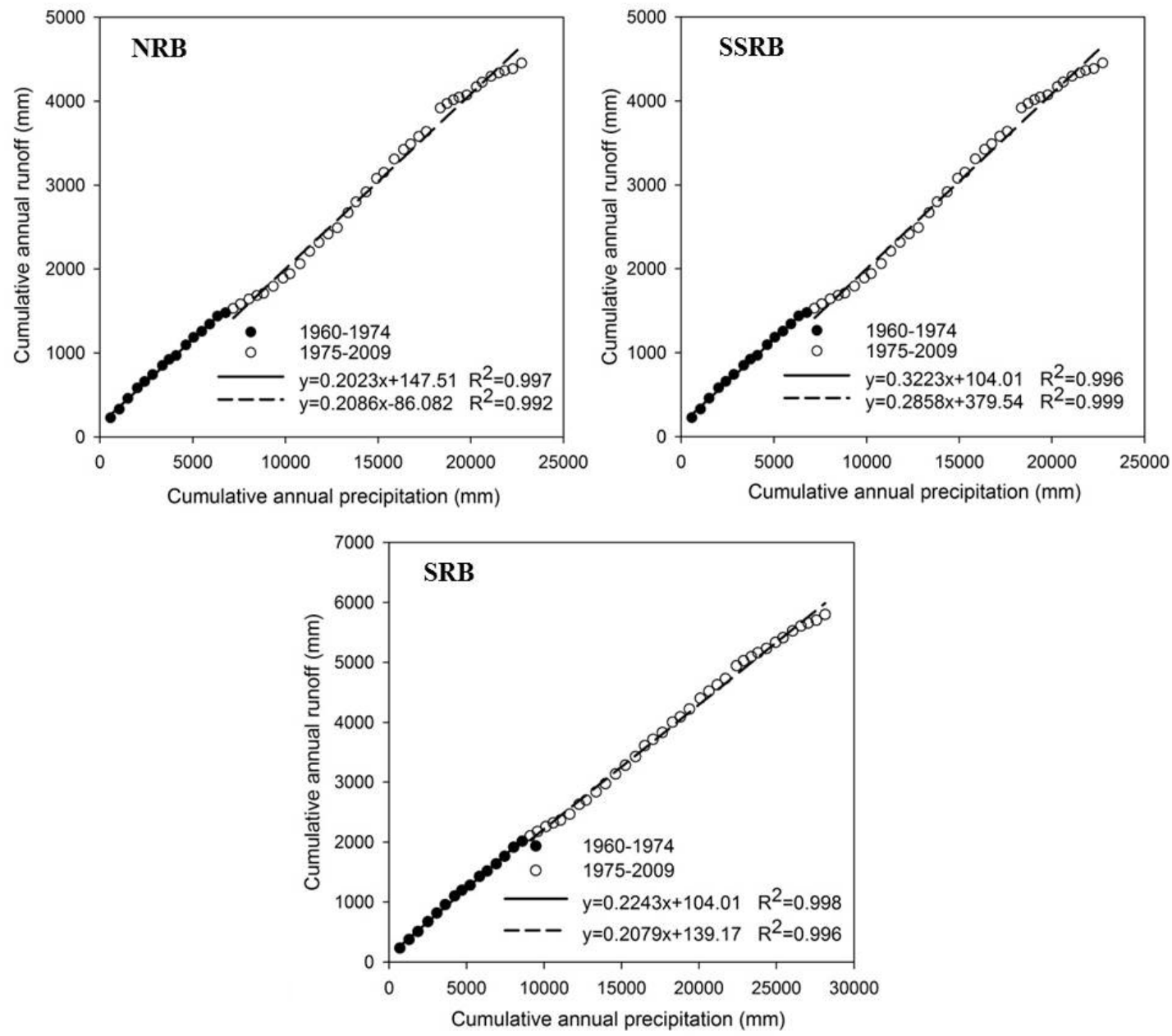

\subsection{Relative Changes in Precipitation, Potential Evapotranspiration and Runoff for 1960-1974}

Average annual precipitation of 1975-2009 across the Songhua River Basin decreased when compared with that of 1960-1974, with a varying extent of $0.2 \%-8 \%$. For different sub periods, the average annual precipitation decreased by $1 \%$ to $11 \%$ in different sub basins, except that of UNRB, LNRB and LSRB during the 1990s and LNRB between 1975 and 1989 when precipitation received a relative increase (Table 4 ).

Potential evapotranspiration increased by $1 \%$ to $6 \%$ in UNRB and $2 \%$ to $3 \%$ in LNRB, respectively, except 1990 s, when PET decreased by $0.4 \%$ and $1 \%$ respectively in UNRB and LNRB. As for that in USSRB, the PET increased by $0.5 \%$ in $1975-1989$, while it decreased by $3 \%$ and $2 \%$ respectively in the 1990s and the 2000s. Both the PET in LSSRB and LSRB increased over different periods, except for the slightly decrease in the 1990s (Table 4). 
Average runoff for the whole period of 1975-2009 in the five basins decreased by $3 \%$ to $24 \%$, compared with that of 1960-1974 (Table 4). In SSRB and LSRB, runoff decreased in all the three sub-periods, more obviously in 1975-1989 and 2000-2009. However, the detailed changing characteristics of runoff in NRB were various. In UNRB, runoff increased by $2 \%$ and $10 \%$ respectively in 1975-1989 and 1990-1999, while it decreased by 24\% in 2000-2009. Nonetheless, the runoff in LNRB decreased by $12 \%$ and $55 \%$ in $1975-1989$ and in $2000-2009$, but increased by $20 \%$ in 1990-1999.

Table 4. Changes in precipitation, PET, and runoff during different periods in the Upper Nenjiang River Basin (UNRB), Lower Nenjiang River Basin (LNRB), Upper Second Songhua River Basin (USSRB), Lower Second Songhua River Basin (LSSRB), and Lower Songhua River Basin (LSRB) in Northeast China.

\begin{tabular}{|c|c|c|c|c|c|c|c|}
\hline \multirow{2}{*}{ Basin } & \multirow{2}{*}{ Period } & \multicolumn{2}{|c|}{$\Delta \mathbf{P}$} & \multicolumn{2}{|c|}{$\triangle$ PET } & \multicolumn{2}{|c|}{$\Delta \mathbf{R}$} \\
\hline & & $\mathbf{m m}$ & $\%$ & $\mathbf{m m}$ & $\%$ & $\mathbf{m m}$ & $\%$ \\
\hline \multirow{5}{*}{ UNRB } & 1960-1974 & - & - & - & - & - & - \\
\hline & 1975-1989 & -5 & -1 & 8 & 1 & 3 & 2 \\
\hline & 1990-1999 & 30 & 6 & -3 & -0.4 & 17 & 10 \\
\hline & 2000-2009 & -26 & -5 & 41 & 6 & -40 & -24 \\
\hline & 1975-2009 & -1 & -0.2 & 14 & 2 & -6 & -3 \\
\hline \multirow{5}{*}{ LNRB } & 1960-1974 & - & - & - & - & - & - \\
\hline & 1975-1989 & 19 & 4 & 21 & 2 & -12 & -12 \\
\hline & 1990-1999 & 40 & 9 & -10 & -1 & 19 & 20 \\
\hline & 2000-2009 & -51 & -11 & 28 & 3 & -51 & -55 \\
\hline & 1975-2009 & 5 & 1 & 14 & 2 & -14 & -14 \\
\hline \multirow{5}{*}{ USSRB } & 1960-1974 & - & - & - & - & - & - \\
\hline & 1975-1989 & -81 & -9 & 4 & 0.5 & -92 & -17 \\
\hline & 1990-1999 & -43 & -5 & -21 & -3 & -62 & -11 \\
\hline & $2000-2009$ & -65 & -8 & -16 & -2 & -132 & -24 \\
\hline & 1975-2009 & -65 & -8 & -9 & -1 & -95 & -17 \\
\hline \multirow{5}{*}{ LSSRB } & 1960-1974 & - & - & - & - & - & - \\
\hline & 1975-1989 & -13 & -2 & 9 & 1 & -32 & -16 \\
\hline & 1990-1999 & -6 & -1 & -5 & -1 & -30 & -15 \\
\hline & 2000-2009 & -38 & -6 & 21 & 3 & -48 & -24 \\
\hline & 1975-2009 & -18 & -3 & 8 & 1 & -36 & -18 \\
\hline \multirow{5}{*}{ LSRB } & 1960-1974 & - & - & - & - & - & - \\
\hline & 1975-1989 & -36 & -6 & 22 & 3 & -26 & -19 \\
\hline & 1990-1999 & 1 & 0.1 & -7 & -1 & -15 & -11 \\
\hline & $2000-2009$ & -52 & -9 & 9 & 1 & -64 & -46 \\
\hline & $1975-2009$ & -30 & -5 & 10 & 1 & -34 & -24 \\
\hline
\end{tabular}

\subsection{Quantitative Assessment of the Impact of Climate Variation and Human Activities on the Runoff}

The effects of climate variation and human activities on runoff in the Songhua River Basin varied spatially and temporally. The quantitative assessment showed that both climate variation and human activities played a negative effect on runoff in UNRB except the period of 1975-1989 and the 1990s 
(Table 5). Generally, climate variation was the dominant factor affecting runoff ( $86 \%$ for $1990-1999$ and 55\% for 2000-2009) in the UNRB except for 1975-1989. With regard to LNRB, human activities played a dominant role in the runoff decline in 1975-1989 and 2000-2009, contributing $83 \%$ and $82 \%$ respectively. However, both climate variation and human activities led to a runoff increase in 1990-1999, and the effect of climate variation accounts for $85 \%$.

Table 5. Contributions of climate variation and human activities on changes in runoff in the Upper Nenjiang River Basin (UNRB), Lower Nenjiang River Basin (LNRB), Upper Second Songhua River Basin (USSRB), Lower Second Songhua River Basin (LSSRB), and Lower Songhua River Basin (LSRB) in Northeast China.

\begin{tabular}{|c|c|c|c|c|c|c|c|c|c|}
\hline \multirow{2}{*}{ Basin } & \multirow{2}{*}{ Period } & \multirow{2}{*}{$\begin{array}{c}\mathbf{R} \\
\mathbf{m m}\end{array}$} & \multirow{2}{*}{$\begin{array}{c}\mathbf{P} \\
\mathbf{m m}\end{array}$} & \multirow{2}{*}{$\begin{array}{l}\text { PET } \\
\mathbf{m m} \\
\end{array}$} & \multirow{2}{*}{$\begin{array}{l}\Delta \mathrm{R} \\
\mathbf{m m}\end{array}$} & \multicolumn{2}{|c|}{$\Delta \mathbf{R}_{\text {clim }}$} & \multicolumn{2}{|c|}{$\Delta \mathbf{R}_{\text {hum }}$} \\
\hline & & & & & & $\mathbf{m m}$ & $\%$ & $\mathbf{m m}$ & $\%$ \\
\hline \multirow{4}{*}{ UNRB } & 1960-1974 & 165 & 507 & 724 & & & & & \\
\hline & 1975-1989 & 168 & 502 & 732 & 3 & -5 & 39 & 8 & 61 \\
\hline & 1990-1999 & 181 & 537 & 721 & 17 & 20 & 86 & -3 & 14 \\
\hline & 2000-2009 & 125 & 481 & 765 & -40 & -22 & 55 & -18 & 45 \\
\hline \multirow{4}{*}{ LNRB } & 1960-1974 & 93 & 447 & 953 & & & & & \\
\hline & 1975-1989 & 82 & 466 & 974 & -12 & 3 & 17 & -14 & 83 \\
\hline & 1990-1999 & 112 & 487 & 943 & 19 & 16 & 85 & 3 & 15 \\
\hline & 2000-2009 & 42 & 396 & 981 & -51 & -9 & 18 & -42 & 82 \\
\hline \multirow{4}{*}{ USSRB } & 1960-1974 & 559 & 861 & 820 & & & & & \\
\hline & 1975-1989 & 467 & 780 & 824 & -92 & -60 & 65 & -32 & 35 \\
\hline & 1990-1999 & 497 & 818 & 799 & -62 & -26 & 42 & -36 & 57 \\
\hline & 2000-2009 & 427 & 795 & 805 & -132 & -44 & 34 & -88 & 66 \\
\hline \multirow{4}{*}{ LSSRB } & 1960-1974 & 202 & 671 & 835 & & & & & \\
\hline & 1975-1989 & 170 & 658 & 845 & -32 & -8 & 27 & -23 & 73 \\
\hline & 1990-1999 & 172 & 665 & 830 & -30 & -2 & 6 & -28 & 94 \\
\hline & 2000-2009 & 154 & 633 & 856 & -48 & -18 & 38 & -30 & 62 \\
\hline \multirow{4}{*}{ LSRB } & 1960-1974 & 140 & 586 & 840 & & & & & \\
\hline & 1975-1989 & 114 & 551 & 862 & -26 & -17 & 63 & -10 & 37 \\
\hline & 1990-1999 & 125 & 587 & 833 & -15 & 2 & 9 & -17 & 91 \\
\hline & 2000-2009 & 76 & 534 & 848 & -64 & -14 & 23 & -50 & 78 \\
\hline
\end{tabular}

For USSRB and LSSRB, both climate variation and human activities had a negative effect on runoff in all the time periods. In USSRB, climate variation contributed more (65\%) to the runoff decline before 1989. The reduction of runoff due to human activities became larger from $57 \%$ in $1990-2000$ to $66 \%$ in 2000-2009. In LSSRB, the effect of human activities was the dominant factor for the decrease of runoff, with the largest contribution in 1990-1999 (94\%).

In respect of LSRB, the impacts of climate variation and human activities on runoff were negative during all the durations except for the positive effect of climate variation in 1990-1999. Human activities played a more important role, with the contribution varying from $62 \%$ to $70 \%$. For different periods, both the impacts of climate and human activities on runoff increased, and the increasing extent of change in runoff caused by human activities was larger. 


\section{Discussion}

Several studies reported a decrease in precipitation [6,40] and an increase in PET [41] in the Songhua River Basin. Overall, our findings showed similar trends in precipitation and PET for the entire SRB. However, the specific changing characteristics were found to be various among the five sub river basins and different sub periods in our study. Apart from the decreasing trend in streamflow of the SRB reported by other researchers [27,42], our study identified a change-point of the year of 1974 for runoff. The results showed that the average runoff during the last 35 years declined in all sub river basins of the SRB when compared with that of the previous 15 years before 1974.

The change of runoff was closely related to the variations of precipitation and PET. However, human activities also played an important role in runoff change. Recent studies have attempted to quantify the impact of climate variability on runoff under land use change [19,22,25,43,44]. In the following sections, we discuss how the runoff responses to climate variation and human activities based on our findings. However, it is essential to point out that we attempted to identify the individual impact of climate variation and human activities on runoff and supposed them to be independent in this paper. In reality, land use/cover can be influenced by both climate variation and human activities and climate variation can also be affected by human activities.

\subsection{Contribution of Climate Variation to Runoff Change in SRB}

Generally, climate variation played a negative effect on runoff in the Songhua River Basin. However, runoff in LNRB increased by $19 \mathrm{~mm}$ due to climate variation in 1975-1989. As presented in Table 4, both the mean annual precipitation and PET of 1975-1989 increased compared with the period of 1960-1974, but the increase in proportion of precipitation was larger than that of PET. In addition, the runoff was more sensitive to precipitation than PET according to the results of $\beta$ and $\gamma$ in our calculating process. The combination of these two reasons led to the positive effect of climate variation on the runoff during 1975-1989 in LNRB. Similarly, the runoff increase caused by climate variation between 1990 and 1999 in UNRB, LNRB and LSRB can mainly be attributed to the increase of precipitation and decrease of PET during this period (Table 4).

In LSSRB, human activities played a dominant role in runoff decline and the impact in 1990-1999 was much larger than that of other periods. This can be explained from the aspect of climate impact: compared to the period of 1960-1974, the precipitation reduced less in 1990-1999 than in other periods and the PET decreased during this period while increased in other periods (Table 4), which may lead to less reduction of runoff due to climate variation. At the same time, there was not so much difference between the total reduction of runoff in 1990-1999 and that in other periods. All the above resulted in the largest portion of reduction in runoff caused by human activities in 1990-1999 in LSSRB.

\subsection{Contribution of Human Activities to Runoff Change in SRB}

Land use/cover in the Songhua River Basin has changed substantially since the 1970s (Table 6). The area of forest in 2005 has decreased by $9.6 \%, 5.4 \%$, and $6.5 \%$, respectively, in NRB, SSRB, and LSRB when compared with that of 1975 (Table 6). However, there is an increase in area of residential and industrial land, especially in the $1980 \mathrm{~s}$ and the $1990 \mathrm{~s}$, when the area increased by $380 \%, 410 \%$ and 
$470 \%$, respectively, in NRB, SSRB and LSRB. The increasing area reveals an increasing water demand in domestic and industry that could aggravate the conflict in water supply and demand. In addition, with the rapid growth of population, the Chinese government promoted the region to become China's future major grain production base over recent years. The area of cultivated land expanded, which was most obvious in the NRB. The area of paddy land in 2005 increased by more than $175 \%$ than that of 1975 (Table 6). The increasing water demand for agriculture irrigation would consequently increase the water consumption.

Table 6. Land use in 1975, 1986, 1996 and 2005 in the Nenjiang River Basin (NRB), Second Songhua River Basin (SSRB), and Lower Songhua River Basin (LSRB) in Northeast China.

\begin{tabular}{|c|c|c|c|c|c|c|c|c|c|c|}
\hline Basin & $\begin{array}{l}\text { Time } \\
\text { Stage }\end{array}$ & $\begin{array}{c}\text { Paddy } \\
\text { Land } \\
\left(\mathbf{1 0}^{3} \mathbf{k m}^{2}\right) \\
\end{array}$ & $\begin{array}{l}\text { Dry Land } \\
\left(10^{3} \mathbf{k m}^{2}\right)\end{array}$ & $\begin{array}{c}\text { Forest } \\
\left(10^{3} \mathbf{k m}^{2}\right)\end{array}$ & $\begin{array}{l}\text { Grassland } \\
\left(10^{3} \mathbf{k m}^{2}\right)\end{array}$ & $\begin{array}{c}\text { Water } \\
\left(10^{3} \mathbf{k m}^{2}\right)\end{array}$ & $\begin{array}{c}\text { Reservoir } \\
\& \text { Pond } \\
\left(10^{3} \mathbf{k m}^{2}\right) \\
\end{array}$ & $\begin{array}{c}\text { Residential } \\
\text { \& Industry } \\
\left(\mathbf{1 0}^{3} \mathbf{k m}^{\mathbf{2}}\right) \\
\end{array}$ & $\begin{array}{c}\text { Bared } \\
\text { Land } \\
\left(\mathbf{1 0}^{3} \mathbf{k m}^{\mathbf{2}}\right) \\
\end{array}$ & $\begin{array}{l}\text { Wetland } \\
\left(10^{3} \mathrm{~km}^{2}\right)\end{array}$ \\
\hline \multirow{4}{*}{ NRB } & 1975 & 1.88 & 82.5 & 113 & 49.1 & 5.55 & 0.374 & 1.13 & 9.46 & 30.5 \\
\hline & 1986 & 1.87 & 80.7 & 97.6 & 68.4 & 7.91 & 0.380 & 5.50 & 11.1 & 19.5 \\
\hline & 1996 & 4.80 & 85.1 & 98.4 & 62.3 & 7.34 & 0.493 & 5.47 & 9.27 & 19.8 \\
\hline & 2005 & 5.17 & 100 & 102 & 38.5 & 6.00 & 0.488 & 1.80 & 11.5 & 27.7 \\
\hline \multirow{4}{*}{ SSRB } & 1975 & 5.05 & 25.3 & 39.9 & 1.27 & 0.682 & 0.502 & 0.556 & 0.151 & 0.486 \\
\hline & 1986 & 5.58 & 24.8 & 35.8 & 1.54 & 1.22 & 0.734 & 3.22 & 0.232 & 0.249 \\
\hline & 1996 & 5.78 & 24.5 & 35.4 & 1.65 & 1.21 & 0.673 & 3.46 & 0.218 & 0.346 \\
\hline & 2005 & 6.06 & 26.7 & 37.8 & 0.846 & 0.675 & 0.495 & 0.875 & 0.173 & 0.295 \\
\hline \multirow{4}{*}{ LSRB } & 1975 & 10.9 & 58.8 & 97.3 & 6.14 & 3.49 & 0.428 & 1.17 & 0.669 & 7.79 \\
\hline & 1986 & 10.9 & 60.6 & 90.6 & 7.14 & 7.35 & 0.654 & 4.80 & 26.5 & 6.00 \\
\hline & 1996 & 11.8 & 62.5 & 88.9 & 6.70 & 6.38 & 0.624 & 4.94 & 27.1 & 6.21 \\
\hline & 2005 & 14.7 & 63.8 & 91.0 & 5.00 & 3.46 & 0.591 & 1.67 & 0.803 & 5.72 \\
\hline
\end{tabular}

Additionally, many hydraulic projects (e.g., Chaersen Reservoir, Baishan and Nierji Hydropower Stations) were constructed to meet the agricultural, industrial and domestic water demands in the SRB in recent years. On the one hand, the storage of hydraulic projects may lead to a runoff decline in the downstream directly. On the other hand, the hydraulic projects may cause an increase of PET and influence runoff indirectly. Moreover, the hydraulic projects not only change the distribution of seasonal water resource, but also re-distribute the inter-annual runoff.

\subsection{Uncertainty of the Hydrological Sensitivity Analysis}

Some uncertainties may exist in the hydrologic sensitivity analysis method when assessing the effects of climate variation and human activities on runoff. First, the method is based on long-term hydro-meteorological observation data. The limited number and distribution of hydro-meteorological stations may affect the simulation accuracy of the hydro-climatic variables such as PET, runoff, and AET in this method. In addition, the method assumes that human activities and climate variation are independent of each other [45]. However, climate variation may influence human activities such as land use, and human activities such as extensive urbanization and expanded population may cause changes in climate. Thus, these two factors are inter-related, and due to the limited length of data combined with the 
insufficiency in change-point analysis, there were some human disturbances during the natural period. Uncertainty may also arise from the parameter of $w$ in the method.

Despite of the uncertainties and limitations, our study sheds light in understanding of the sensitivity of runoff to climate variation and human activities in the Songhua River Basin, where water is crucial for grain-production and the wetland ecosystem. In addition, more work will be carried out on the estimation of these uncertainties in our future studies to improve the results of quantification.

\section{Conclusions}

In this study, we investigated the impacts of climatic variability and human activities on a 50-year long trend of runoff in the Songhua River Basin, Northeast China. We found a clear downward trend in the river basin's runoff, accompanied by a declining trend of precipitation. However, the runoff decline was much greater than the precipitation decline, especially after 1974 when large-scale land use change and river engineering projects had been undertaken. The contribution of climate variation and human activities varied temporally and spatially. Generally, human activities contributed $62 \%-82 \%$ to the reduction of runoff for the entire study period of 1975-2009. However, climate variation was the main factor leading to the runoff increase in 1990-1999 in UNRB and LNRB as a result of the increase in precipitation and decrease in PET. Due to the more intensive human activities in the downstream basins, the effects of human activities were relatively stronger in the lower basin areas than in the upper basin areas. However, the impact of human activities in the upper basins has been increasing with more land development. Based on the findings we suggest adaptive management strategies to avoid the risk of water resources shortage in this region.

\section{Acknowledgments}

The research was jointly funded by the National Basic Research Program of China (No. 2010CB428404), Key Research Program of Chinese Academy of Sciences (KSZD-EW-Z-021), the CAS/SAFEA International Partnership Program for Creative Research Teams, and Scientific Research Project of Public Welfare Industry of the Ministry of Water Resources, China (No. 201401014). We thank all members of our Hydrology and Water Resources Research Group.

\section{Author Contributions}

All authors contributed to the design and development of this manuscript. Fengping Li carried out the data analysis and prepared the first draft of the manuscript; Guangxin Zhang is the graduate advisor of Fengping Li and contributed many ideas to the study; Yi Jun Xu provided important advice on the concept of methodology and structuring of the manuscript, as well as edited the manuscript prior to submission and during revisions.

\section{Conflicts of Interest}

The authors declare no conflict of interest. 


\section{References}

1. Banasik, K.; Hejduk, L. Long-term changes in runoff from a small agricultural catchment. Soil Water Res. 2012, 7, 64-72.

2. Banasik, K.; Hejduk, L.; Hejduk, A.; Kaznowska, E.; Banasik, J.; Byczkowski, A. Long-term variability of runoff from a small catchment in the region of the Kozienice Forest. Sylwan 2013, $157,578-586$.

3. Pekarova, P.; Miklanek, P.; Pekar, J.; Demuth, S.; Gustard, A.; Planos, E.; Scatena, F.; Servat, E. Long-term trends and runoff fluctuations of European rivers. In Climate Variability and Change-Hydrological Impacts. Proceedings of the Fifth FRIEND World Conference, Havana, Cuba, 27 November-1 December 2006; pp. 520-525.

4. Shi, C.X.; Zhou, Y.Y.; Fan, X.L.; Shao, W.W. A study on the annual runoff change and its relationship with water and soil conservation practices and climate change in the middle Yellow River basin. Catena 2013, 100, 31-41.

5. Hao, X.M.; Chen, Y.N.; Xu, C.C. Impacts of climate change and human activities on the surface runoff in the Tarim River basin over the last fifty years. Water Resour. Manag. 2008, 22, $1159-1171$.

6. Li, F.P.; Zhang, G.X.; Xu, Y.J. Spatiotemporal variability of climate and streamflow in the Songhua River Basin, Northeast China. J. Hydrol. 2014, 514, 53-64.

7. Zhan, C.S.; Jiang, S.S.; Sun, F.B.; Jia, Y.W.; Niu, C.W.; Yue, W.F. Quantitative contribution of climate change and human activities to runoff changes in the Wei River basin, China. Hydrol. Earth Syst. Sci. 2014, 18, 3069-3077.

8. Zhang, X.; Zhang, L.; Zhao, J.; Rustomji, P.; Hairsine, P. Responses of streamflow to changes in climate and land use/cover in the Loess Plateau, China. Water Resour. Res. 2008, 44, doi:10.1029/2007WR006711.

9. Wang, D.B.; Mohanmad, H. Quantifying the relative contribution of the climate and direct human impacts on mean annual streamflow in the contiguous United States. Water Resour. Res. 2011, 47, doi:10.1029/2010WR010283.

10. Ye, B.S.; Yang, D.Q.; Kane, D.L. Changes in Lena River streamflow hydrology: Human impacts versus natural variations. Water Resour. Res. 2003, 39, doi:10.1029/2003WR001991.

11. Tian, F.; Yang, Y.H.; Han, S.M. Using runoff slope-break to determine dominate factors of runoff decline in Hutuo River Basin, North China. Water Sci. Technol. 2009, 60, 2135-2144.

12. Li, D.F.; Tian, Y.; Liu, C.M. Distributed hydrological simulation of the source regions of the Yellow River under environmental changes. Acta Geogr. Sin. 2004, 59, 565-573. (In Chinese)

13. Wang, G.S.; Xia, J.; Chen, J. Quantification of effects of climate variations and human activities on runoff by a monthly water balance model: A case study of the Chaobai River basin in Northern China. Water Resour. Res. 2009, 45, doi:10.1029/2007WR006768.

14. Montenegro, A.; Ragab, R. Hydrological response of a Brazilian semi-arid catchment to different land use and climate change scenarios: A modelling study. Hydrol. Process. 2010, 24, 2705-2723.

15. Dooge, J.C.I.; Bruen, M.; Parmentier, B. A simple model for estimating the sensitivity of runoff to long-term changes in precipitation without a change in vegetation. Adv. Water. Resour. 1999, 23, $153-163$. 
16. Milly, P.C.D.; Dunne, K.A. Macroscale water fluxes 2. Water and energy supply control of their inter-annual variability. Water Resour. Res. 2002, 38, doi:10.1029/2001WR000760.

17. Sankarasubramanian, A.; Vogel, R.M.; Limbrunner, J.F. Climate elasticity of streamflow in the United States. Water Resour. Res. 2001, 37, 1771-1781.

18. Jones, R.N.; Chiew, F.H.S.; Boughtom, W.C.; Zhang, L. Estimating the sensitivity of mean annual runoff to climate change using selected hydrological models. Adv. Water Resour. 2006, 29, 1419-1429.

19. Li, L.-J.; Zhang, L.; Wang, H.; Wang, J.; Yang, J.-W.; Jiang, D.-J.; Li, J.-Y.; Qin, D.-Y. Assessing the impact of climate variability and human activities on streamflow from the Wuding River basin in China. Hydrol. Process. 2007, 21, 3485-3491.

20. Liu, Q.; Yang, Z.; Cui, B.; Sun, T. Temporal trends of hydro-climatic variables and runoff response to climatic variability and vegetation changes in the Yiluo River basin, China. Hydrol. Process. 2009, 23, 3030-3039.

21. Zhao, F.F.; Zhang, L.; Xu, Z.X.; David, F.S. Evaluation of methods for estimating the effects of vegetation change and climate change on streamflow. Water Resour. Res. 2010, 46, doi:10.1029/2009WR007702.

22. Wang, W.G.; Shi, Q.X.; Yang, T.; Peng, S.Z.; Xing, W.Q.; Sun, F.C.; Luo, Y.F. Quantitative assessment of the impact of climate variability and human activities on runoff changes: A case study in four catchments of the Haihe River basin, China. Hydrol. Process. 2013, 27, 1158-1174.

23. Milly, P.C.D.; Dunne, K.A.; Vecchia, A.V. Global pattern of trends in streamflow and water availability in a changing climate. Nature 2005, 438, 347-350.

24. Wei, X.H.; Zhang, M.F. Quantifying streamflow change caused by forest disturbance at a large spatial scale: A single watershed study. Water Resour. Res. 2010, 46, doi:10.1029/2010WR009250.

25. Jiang, S.; Ren, L.; Yong, B.; Singh, V.P.; Yang, X.; Yuan, F. Quantifying the effects of climate variability and human activities on runoff from the Laohahe basin in northern China using three different methods. Hydrol. Process. 2011, 25, 2492-2505.

26. Dong, L.Q.; Zhang, G.X. The dynamic evolvement and hydrological driving factors of marsh in Nenjiang River basin. Adv. Water Sci. 2013, 24, 177-183. (In Chinese)

27. Mu, X.M.; Li, Y.; Gao, P.; Shao, H.B.; Wang, F. The runoff declining process and water quality in Songhuajiang River catchment, China under global climatic change. Clean Soil Air Water 2012, 40, 394-401.

28. Xu, D.X.; Zhang, G.X.; Yin, X.R. Runoff variation and its impacting factor in Nenjiang River during 1956-2006. Adv. Water Sci. 2009, 20, 416-421. (In Chinese)

29. Meng, D.J.; Mo, X.G. Assessing the effect of climate change on mean annual runoff in the Songhua River basin, China. Hydrol. Process. 2012, 26, 1050-1061.

30. Allen, R.G.; Pereira, L.S.; Raes, D.; Smith, M. Crop Evapotranspiration-Guidelines for Computing Crop Water Requirements; FAO Irrigation and Drainage Paper 56; Food and Agriculture Organization of the United Nations: Rome, Italy, 1998; p. 300.

31. Mann, H.B. Non-parametric tests against trend. Econometrica 1945, 13, 245-259.

32. Kendall, M.G. Rank Correlation Methods; Griffin: London, UK, 1975. 
33. Chattopadhyay, S.; Jhajharia, D.; Chattopadhyay, G. Trend estimation and univariate forecast of the sunspot numbers: Development and Comparison of ARMA, ARIMA and Autoregressive Neural Network models. C. R. Geosci. 2011, 343, 433-442.

34. Jhajharia, D.; Dinpashoh, Y.; Kahya, E.; Singh, V.P.; Fakheri-Fard, A. Trends in reference evapotranspiration in the humid region of northeast India. Hydrol. Process. 2012, 26, 421-435.

35. Von Storch, V.H. Misuses of statistical analysis in climate research. In Analysis of Climate Variability: Applications of Statistical Techniques; von Storch, H., Navarra, A., Eds.; Springer-Verlag: Berlin, Germany, 1995; pp. 11-26.

36. Matouškov, M.; Kliment, Z. Runoff changes in the Šumava Mountains (black forest) and the foothill regions: Extent of influence by human impact and climate change. Water Resour. Manag. 2009, 23, 1813-1834.

37. Ma, Z.M.; Kang, S.Z.; Zhang, L.; Tong, L.; Su, X.L. Analysis of impacts of climate change and human activity on streamflow for a river basin in arid region of northwest China. J. Hydrol. 2008, 352, 239-249.

38. Zhang, L.; Dawes, W.R.; Walker, G.R. The response of mean annual evapotranspiration to vegetation changes at catchment scale. Water Resour. Res. 2001, 37, 701-708.

39. Koster, R.D.; Suarez, M.J. A simple framework for examining the interannual variability of land surface moisture fluxes. J. Clim. 1999, 12, 1911-1917.

40. Lu, Z.H.; Xia, Z.Q.; Yu, L.L.; Wang, J.C. Variation of characteristics of annual precipitation and seasonal precipitation in Songhuajiang River Basin. J. China Hydrol. 2012, 32, 62-71. (In Chinese)

41. Liu, C.M.; Zhang, D.; Liu, X.M.; Zhao, C.S. Spatial and temporal change in the potential evapotranspiration sensitivity to meteorological factors in China (1960-2007). J. Geogr. Sci. 2012, 22, 3-14.

42. Li, D.L.; Wang, W.S.; Hu, S.X.; Li, Y.Q. Characteristics of annual runoff variation in major rivers of China. Hydrol. Process. 2012, 26, 2866-2877.

43. Hu, S.S.; Liu, C.M.; Zheng, H.X.; Wang, Z.G.; Yu, J.J. Assessing the impacts of climate variability and human activities on streamflow in the water source area of Baiyangdian Lake. J. Geogr. Sci. 2012, 22, 895-905.

44. Guo, Y.; Li, Z.J.; Mark, A.B.; Deng, P.; Huang, P.N. Quantitative assessment of the impact of climate variability and human activities on runoff changes for the upper reaches of Weihe River. Stoch. Environ. Res. Risk Assess. 2014, 28, 333-346.

45. Zheng, H.; Zhang, L.; Zhu, R.; Liu, C.; Sato, Y.; Fukushima, Y. Responses of streamflow to climate and land surface change in the headwaters of the Yellow River Basin. Water Resour. Res. 2009, 45, doi:10.1029/2007WR006665.

(C) 2014 by the authors; licensee MDPI, Basel, Switzerland. This article is an open access article distributed under the terms and conditions of the Creative Commons Attribution license (http://creativecommons.org/licenses/by/4.0/). 